\title{
Failure to induce secretion in jejunal biopsies from children with cystic fibrosis
}

\author{
C J TAYLOR, P S BAXTER, J HARDCASTLE, AND P T HARDCASTLE \\ From the Department of Paediatrics, Children's Hospital, Sheffield and Department of Physiology, The \\ University, Sheffield
}

SUMmARY The secretory activity of jejunal biopsies from children with cystic fibrosis (CF) has been investigated using a modified Ussing chamber technique. Samples from six children with CF failed to respond when challenged with the intestinal secretagogues acetylcholine $\left(10^{-3} \mathrm{M}\right)$, prostaglandin $\mathrm{E}_{2}$ $\left(1 \cdot 4 \times 10^{-6} \mathrm{M}\right)$ and dibutyryl cyclic AMP $\left(10^{-3} \mathrm{M}\right)$, while control tissues exhibited rises in short circuit current of $28 \cdot 1(7 \cdot 4)(6) \mu \mathrm{A} / \mathrm{cm}^{2}, 23.4(4 \cdot 6)(6) \mu \mathrm{A} / \mathrm{cm}^{2}$ and $10.0(2.0)(4) \mu \mathrm{A} / \mathrm{cm}^{2}$ respectively in response to these agents. The calcium ionophore, $A 23187\left(3 \cdot 8 \times 10^{-6} \mathrm{M}\right)$, increased the short circuit current in all the control tissues (mean change $\left.=10 \cdot 1(2 \cdot 7)(5) \mu \mathrm{A} / \mathrm{cm}^{2}\right)$ and induced a small response in some of the CF tissues. Both groups of tissues generated a rise in short circuit current associated with sodium linked glucose $(10 \mathrm{mM} / \mathrm{l})$ absorption (control $=32 \cdot 6(9 \cdot 3)(6) \mu \mathrm{A} / \mathrm{cm}^{2}, \mathrm{CF}=36 \cdot 2(13 \cdot 9)(6)$ $\left.\mu \mathrm{A} / \mathrm{cm}^{2}, \mathbf{p}>\mathbf{0 . 0 5}\right)$. These results show that the defect in chloride transport observed in other epithelia in $\mathrm{CF}$ also exists in the jejunum and could contribute to the intestinal effects of the disease. The technique used should permit further studies of the basic defect and may be of diagnostic value.

Cystic fibrosis (CF) is a single gene defect that involves secretory epithelia. The demonstration of abnormal chloride movement across sweat duct epithelium,' respiratory epithelium,,$^{2}$ and placental trophoblast tissue ${ }^{3}$ has prompted speculation that the disease results from a specific defect in chloride transport. The mechanism of chloride transport across epithelia involves two steps. ${ }^{+}$Chloride is taken up at one side of the cell against its electrochemical gradient via a $\mathrm{Na}-\mathrm{K}_{-}-\mathrm{Cl}_{2}$ symport which harnesses the energy from the sodium gradient. The accumulated chloride can then be released at the other side of the cell through specific chloride channels in the membrane. Recent evidence suggests that it is the action of these channels that is impaired in CF. ${ }^{5 n}$

The intestinal epithelium secretes chloride by a mechanism whose characteristics conform to those described above. ${ }^{+}$Although gastrointestinal manifestations of $\mathrm{CF}$ are common, it is not known whether they are related to impaired chloride transport in the enterocyte. In the normal intestine, chloride se-

Address for correspondence: Dr C J Taylor, Department of Pacdiatrics. Children's Hospital. Western Bank, Sheffield S10 $2 \mathrm{TH}$

Received for publication 12 February 1988. cretion can be stimulated by a variety of agents ${ }^{\mathrm{x}}$ and as it is an electrogenic process, this response can be detected as an increase in transintestinal electrical activity. ${ }^{+}$To determine whether intestinal chloride transport was affected in CF the secretory responses of jejunal biopsies taken from children suffering from the disease were compared with the responses of biopsies taken from non-CF controls. A preliminary report of the findings has been published."

\section{Methods}

PATIENTS

Six children with $C F$, mean age 7.8 years (range two years two months to 16 years five months) were studied. In each case the diagnosis of $\mathrm{CF}$ was confirmed by at least two consecutively abnormal sweat tests. All had steatorrhoea at presentation and were receiving pancreatic enzyme supplements which were discontinued 12 hours before biopsy. Of these patients, one underwent biopsy as part of a malabsorption screen before a positive sweat test and in two further patients the diarrhoea was found to be associated with giardiasis or lactose intolerance. The three remaining $\mathrm{CF}$ children had persisting steatorr- 
hoea and poor weight gain despite high dose microsphere enzyme supplements $\pm \mathrm{H}_{2}$ blockers. One was subsequently found to have bacterial overgrowth secondary to a blind loop. Six children with normal sweat tests under investigation for chronic nonspecific diarrhoea (3) or short stature (3) served as controls. Their mean age was $4 \cdot 1$ years (range three months to 11 years eight months). Jejunal morphology in both groups of children was normal. Three children with abnormal mucosae from coeliac disease (2) or post enteritis malabsorption (1) were also studied. Their results are reported separately.

\section{EXPERIMENTAL PROCEDURE}

Jejunal biopsies were obtained using a standard double port paediatric Crosby capsule, with samples taken under fluroscopic control at or about the ligament of Treitz. Tissue was removed without delay and after orientation, was mounted as a sheet (exposed area $2 \mathrm{~mm}$ diameter) in a modified Ussing chamber and incubated at $37^{\circ} \mathrm{C}$ with Kreb's bicarbonate saline gassed with $95 \% \mathrm{O}_{2} / 5 \% \mathrm{CO}_{2}$. The serosal solution contained $10 \mathrm{mM} / \mathrm{l}$ glucose while the mucosal solution contained $10 \mathrm{mM} / \mathrm{l}$ mannitol and each had a volume of $5 \mathrm{ml}$. The potential difference (pd) was measured using salt bridge electrodes which were connected via calomel half cells to a differential input electrometer. Current was applied across the tissue using $\mathrm{Ag} / \mathrm{AgCl}$ electrodes which made contact with mucosal and serosal solutions via wide bore salt bridges. Tissue resistance was calculated from the pd change induced by passing a current of $10 \mu \mathrm{A}$ across the intestinal sheet and subtracting from this the resistance of the medium. This was determined in a similar manner in the absence of the tissue. The current generated by the tissue, the short circuit current (SCC), is a reflection of net electrogenic ion movement and was calculated from pd and resistance measurements using Ohm's law. After setting up, and a $10 \mathrm{~min}$ stabilisation period, the pd and resistance were measured at $1 \mathrm{~min}$ intervals. For each test substance, readings were taken for five minutes before and 10 minutes after its addition. At the end of this period the test substance was removed and fresh medium added to the preparation. After five minutes, during which time the electrical activity had returned to basal levels, the sequence was repeated with another test agent. The response was taken as the difference between the maximum current generated in the presence of the test agent and the current immediately before its addition. The secretagogues tested were acetylcholine $\left(\mathrm{ACh}, 10^{-3} \mathrm{M}\right)$, prostaglandin $\mathrm{E}_{2}\left(\mathrm{PGE}_{2}\right.$, $\left.1.4 \times 10^{\circ} \mathrm{M}\right)$, dibutyryl cyclic adenosine $3^{\prime}, 5^{\prime}$ monophosphate (dibutyryl cyclic AMP, $10^{-3} \mathrm{M}$ ) and the calcium ionphore, A23187 $\left(3.8 \times 10^{\circ} \mathrm{M}\right)$. These

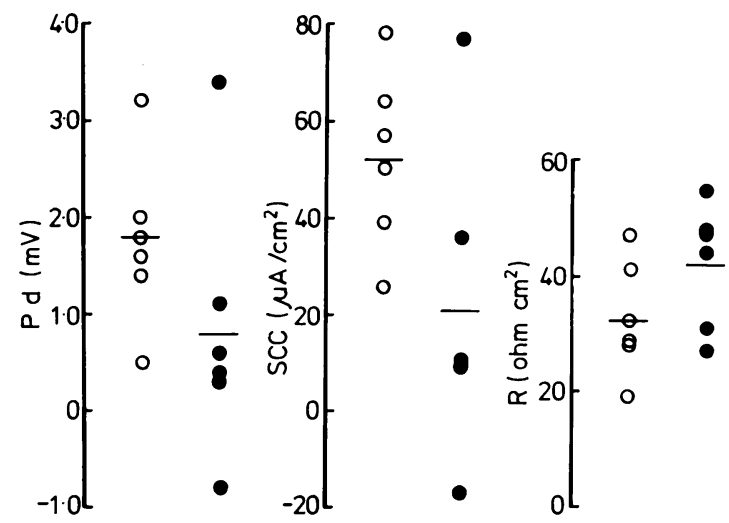

Fig. 1 Basal electrical activity of jejunal mucosac from control $(O)$ and $C F(O)$ patients. The bars indicate the mean values.

were added to the serosal solution to give the concentrations indicated. The rise in SCC induced by $10 \mathrm{mM} / \mathrm{l}$ glucose in the mucosal solution was also measured. The order in which the test agents were added was standardised: $\mathrm{ACh}, \mathrm{PGE}_{2}$, glucose, A23187, and dibutyryl cyclic AMP. The use of an electrical technique to monitor the secretory response avoids any problems that may arise from adherent mucus in the CF biopsies. Histological examination of the tissues after incubation revealed that the crypts of the CF biopsies were not totally occluded by mucus.

\section{CHEMICALS}

Mannitol was obtained from May \& Baker Ltd, Dagenham, England; glucose from BDH Chemicals Ltd, Poole, England; acetylcholine chloride and dibutyryl cyclic AMP from Sigma Chemical Co, St Louis, MO 63178, USA; prostaglandin $E_{2}$ from Upjohn Ltd, Crawley, England, and A23187 from Boehringer Mannheim GmbH, West Germany.

STATISTICAL ANALYSIS

Results are expressed as mean values (1 SE) of the number of observations indicated. The significance of secretagogue and glucose action was assessed using a paired $t$ test. The significance of the difference between control and $\mathrm{CF}$ responses was determined using Fisher's exact test.

\section{Results}

Basal electrical activity of the biopsies is shown in Figure 1. In control biopsies the mean pd was 1.8 $(0 \cdot 4)(6) \mathrm{mV}$, the SCC was $52.2(7 \cdot 5)(6) \mu \mathrm{A} / \mathrm{cm}^{2}$ and the tissue resistance was $32.4(4 \cdot 0)$ (6) $\mathrm{ohm} . \mathrm{cm}^{2}$. Corresponding values for $C F$ jejunum were $(0 \cdot 8(0 \cdot 6)$ 


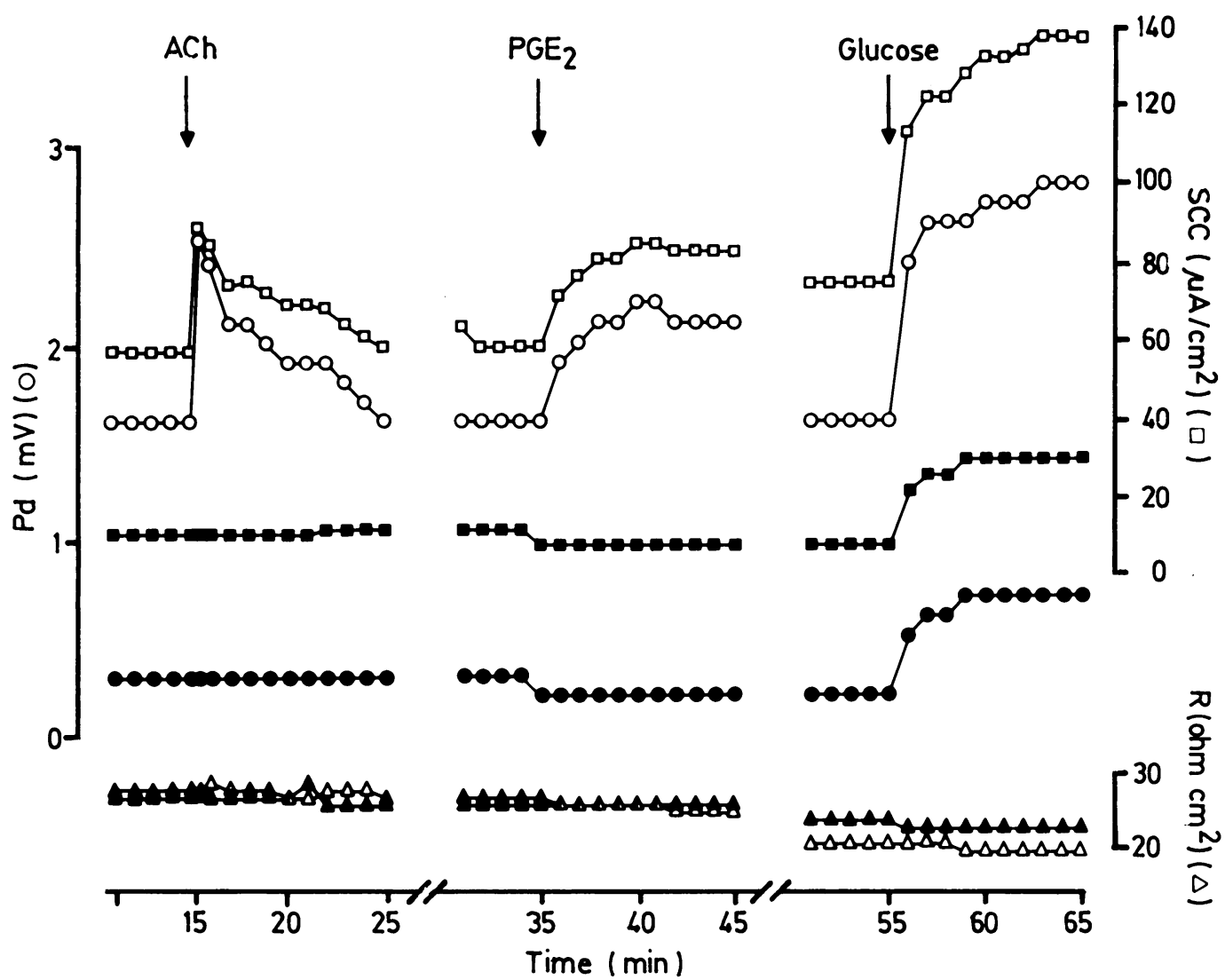

Fig. 2 Examples of electrical activity of jejunal mucosae from a ( $F$ (solid symbols) and a control (open symbols) patient. Pd (circles), $S C C$ (squares) and resistance, $R$ (triangles) are plotted against time. ACh $\left.(10)^{3} \mathrm{M}\right), P G E_{2}\left(1 \cdot 4 \times 10^{\circ} \mathrm{M}\right)$, and glucose $(10 \mathrm{mM} / \mathrm{l})$ were added at the points indicated.

(6) $\mathrm{mV}, 21 \cdot 0(13 \cdot 0)(6) \mu \mathrm{A} / \mathrm{cm}^{2}$ and $42 \cdot 3$ (4.6) (6) ohm. $\mathrm{cm}^{2}$. While the tissue resistances were similar in the two groups $(p>0 \cdot 05)$, the pd and SCC generated by the CF biopsies were generally lower than those obtained in controls, although it was not possible to show a statistically significant difference due to the wide scatter of the values (Fig. 1). Examples of responses obtained from $\mathrm{CF}$ and control biopsies are shown in Fig. 2. The pd and SCC of the control tissue were increased on addition of the secretagogues $\mathrm{ACh}$ and $\mathrm{PGE}_{2}$, and also in the presence of glucose. In contrast, the $\mathrm{CF}$ tissue failed to respond to either $\mathrm{ACh}$ or $\mathrm{PGE}_{2}$, although glucose still induced a rise in $\mathrm{pd}$ and SCC. The tissue resistance of both groups was unaffected by any of the test agents. This pattern of results was observed in all the tissues tested (Fig. 3). The rises in SCC in control tissues were significant, the mean changes being $28 \cdot 1(7 \cdot 4)(6) \mu \mathrm{A} / \mathrm{cm}^{2}$ $(\mathrm{p}<0.05)$ for ACh, $23.4(4.6)(6) \mu \mathrm{A} / \mathrm{cm}^{2}(\mathrm{p}<0.01)$ for $\mathrm{PGE}_{2}$ and $32.6(9.3)(6) \mu \mathrm{A} / \mathrm{cm}^{2}(\mathrm{p}<0.05)$ for glucose. None of the $\mathrm{CF}$ tissues however increased its
SCC in response to either $\mathrm{ACh}$ or $\mathrm{PGE}_{2}(\mathrm{p}>0.05$ in both cases), but they did respond to glucose with a mean rise in SCC $\left(36 \cdot 2(13.9)(6) \mu \mathrm{A} / \mathrm{cm}^{2}, \mathrm{p}<0 \cdot 05\right)$ that did not differ significantly from that obtained in control tissues $(p>0 \cdot 05)$. The difference in the responses of the two groups of tissues to the secretagogues was highly significant $(\mathrm{p}<0 \cdot 005)$.

Agents acting beyond membrane receptor mechanisms also increased the SCC in control tissues (Fig. 4). Dibutyryl cyclic AMP caused a mean rise in SCC of $10 \cdot 0(2 \cdot 0)(4) \mu \mathrm{A} / \mathrm{cm}^{2}$ and $\mathrm{A} 23187$ a rise of $10 \cdot 1$ $(2 \cdot 7)(5) \mu \mathrm{A} / \mathrm{cm}^{2}$. None of the CF tissues responded to dibutyryl cyclic AMP but a small response to A23187 was observed in some CF tissues (Fig. 4).

Tissue sheets from the three children with enteropathies all responded to $\mathrm{ACh}$ and $\mathrm{PGE}_{2}$ with increases in pd and SCC. Their responses to glucose, however, were smaller $\left(5 \cdot 0,3 \cdot 2\right.$, and $\left.0.6 \mu \mathrm{A} / \mathrm{cm}^{2}\right)$ than those obtained in either of the test groups. Subsequent histological examination of these tissues showed abnormalities in mucosal structure. 

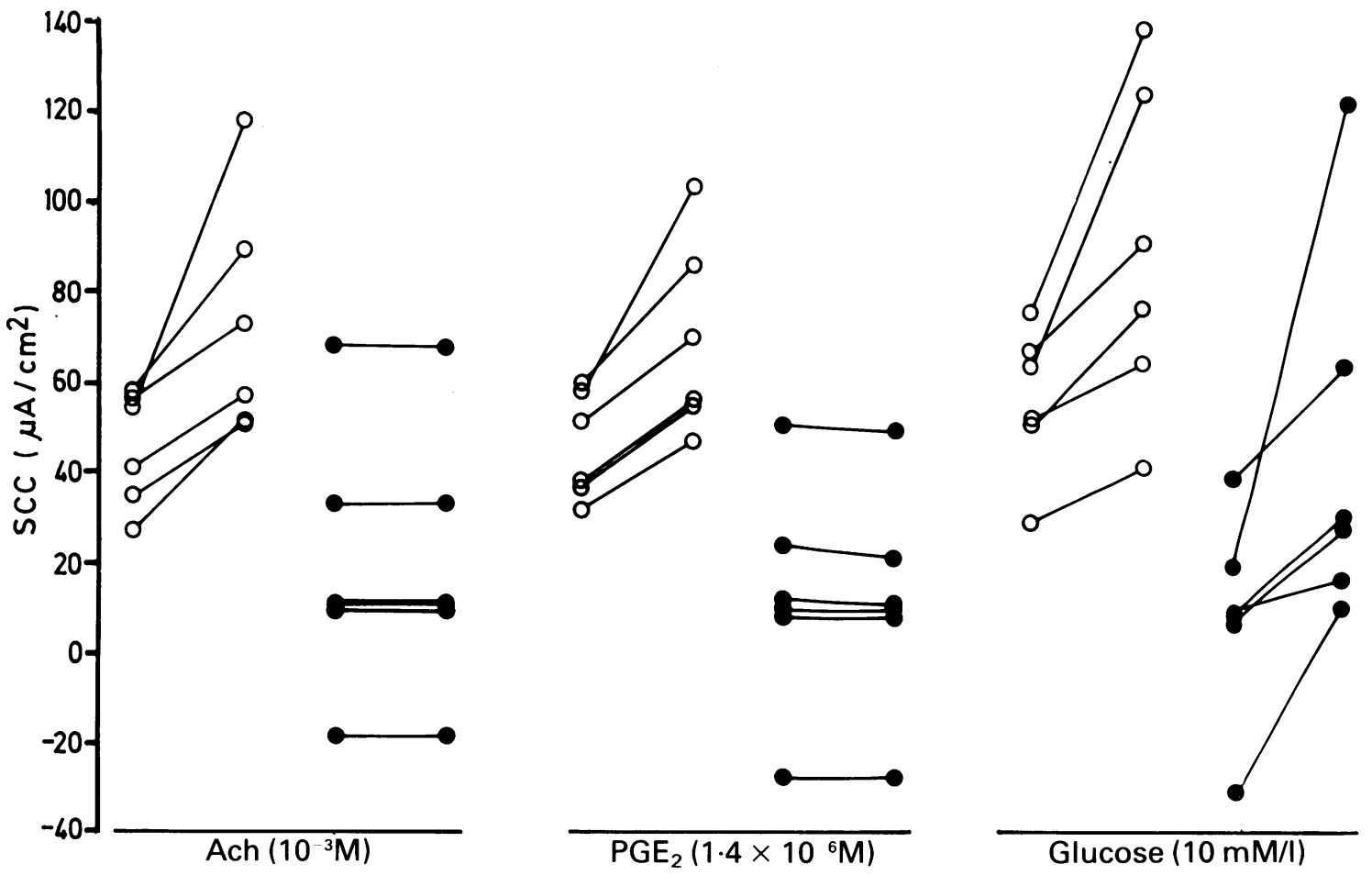

Fig. 3 Comparison of the responses of $C F(O)$ and control $(\bigcirc)$ jejunal mucosae to $A C h\left(10^{-3} M\right), P G E_{2}\left(1 \cdot 4 \times 10^{-6} M\right)$, and glucose $(10 \mathrm{mmol} / \mathrm{l})$. The SCC for each specimen is shown before addition of the test agent and at the peak of the response.

\section{Discussion}

Changes in transepithelial electrical activity have been used to detect abnormalities in ion permeability across microdissected sweat gland ducts, ${ }^{10}$ and respiratory epithelium ${ }^{11}$ from patients with CF. The present study extends this approach to the jejunum and clearly shows that biopsy samples from patients with CF do not possess the ability to respond to known secretagogues, while still exhibiting a normal response to mucosal glucose (Figs 2 and 3 ). A recent study has reported similar findings using larger sheets prepared from intestinal tissue obtained at laparotomy. ${ }^{12}$ The absence of a secretory response appeared to be specific to the CF group as biopsy samples from children with other enteropathies responded normally to secretagogues.

The increased SCC induced by secretagogue challenge in normal intestine has been shown to result from an increase in chloride secretion into the mucosal solution. ${ }^{+}$Secretagogue action in the intestine enhances the chloride permeability of the luminal membrane of the enterocyte, allowing accumulated chloride ions to diffuse out of the cell into the lumen. ${ }^{+}$Evidence is emerging that the chloride channel exists in epithelia from CF patients, but that the mechanism responsible for its regulation

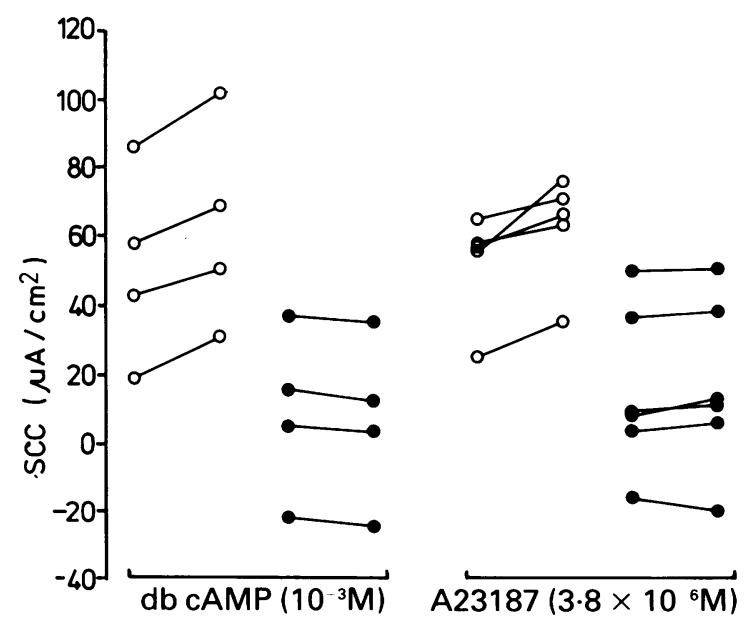

Fig. 4 Comparison of the responses of $C F(O)$ and control (O) jejunal mucosae to dibutyryl cyclic AMP $\left(10^{3} \mathrm{M}\right)$ and $A 23187\left(3 \cdot 8 \times 10^{-6} \mathrm{M}\right)$. The SCC for each specimen is shown before addition of the test agent and at the peak of the response. 
is defective. ${ }^{56}$ The chloride channel in the enterocyte is thought to be activated by a rise in intracellular calcium. ${ }^{13}$ In the case of prostaglandins this change is associated with an enhanced production of cyclic AMP, while ACh acts without altering the level of this nucleotide. ${ }^{13}$ The fact that both $\mathrm{ACh}$ and $\mathrm{PGE}_{2}$ fail to induce a secretory response in the jejunum in $\mathrm{CF}$ suggests that the defect lies beyond the generation of cyclic AMP, as has been reported for other tissues. ${ }^{514}$ This is supported by the failure of exogenous dibutyryl cyclic AMP to elicit a response in $\mathrm{CF}$ jejunum (Fig. 4). The calcium ionophore A23187 induces intestinal secretion by directly raising intracellular calcium levels ${ }^{15}$ and this response was observed in control jejunal biopsies (Fig. 4). A small response to A23187 was also obtained in some of the CF tissues (Fig. 4), suggesting the possibility that the mechanism for raising intracellular calcium may be impaired in CF. Data from other tissues also suggest that it is the regulation of chloride permeability by calcium that is affected by the disease. In the sweat duct normal chloride permeability can be restored by manipulation of calcium levels with A23187 or lanthanum, ${ }^{16}$ while in the respiratory epithelium patch clamp studies have shown that apical membrane chloride channels are present in CF and that they can be activated if intracellular calcium is raised. ${ }^{6}$

In spite of the small size of the biopsy samples, the secretory response was clearly shown. Tissues were easily mounted as sheets with resistances comparable with those of biopsies of adult jejunum investigated in a similar manner, ${ }^{17}$ and also to those reported for much larger sheets of adult human jejunum (2.27 $\mathrm{cm}^{2}$ ) obtained at operation. ${ }^{1 \times}$ The control biopsies responded to secretagogues in a manner that was qualitatively similar to that observed in adult studies with the same secretagogues. ${ }^{18}{ }^{19}$ The lower basal pd and SCC observed in the CF biopsies (Fig. 1) may reflect the absence of endogenous secretion in these tissues. Cystic fibrotic and control samples generated an increased SCC with glucose (Figs 1 and 2). The ionic basis of this effect lies in the increased sodium absorption that occurs in association with glucose transport ${ }^{20}$ and its presence can be used to show tissue viability. Sodium linked nutrient absorption is associated with an increase in the chloride permeability of the luminal membrane ${ }^{21}$ and it has therefore been suggested that the absence of such a chloride permeability change in CF could lead to a decrease in intestinal nutrient absorption. ${ }^{22}$ The fact that the response to glucose in the present study was the same in control and CF tissues (Fig. 3) does not support this view. Although the CF tissues possessed the normal absorptive process for sugars, they did not respond to secretagogues and an inability to secrete electrolytes and fluid may contribute to the intestinal effects of the disease.

The technique presented gives rapid, consistent and reproducible data which clearly distinguishes between control and CF tissues. It would therefore be of diagnostic value in doubtful cases where sweat chloride values are contradictory. Further, it provides an accessible tissue for the laboratory study of the basic defect in CF.

\section{References}

1 Quinton PM. Chloride impermeability in cystic fibrosis. Nature 1983; 301: 421-2.

2 Knowles MR, Stutts MJ, Spock A, Fischer N, Gatzy JT, Boucher RC. Abnormal ion permeation through cystic fibrosis respiratory epithelium. Science 1983; 221: 1067-70.

3 Davis B, Shennan DB, Boyd CAR. Chloride transport in cystic fibrosis placenta. Lancet 1985; i: 392-3.

4 Frizzell RA, Field M, Schultz SG. Sodium-coupled chloride transport by epithelial tissues. Am J Physiol 1979; 236: F1-8.

5 Welsh MJ, Liedtke CM. Chloride and potassium channels in cystic fibrosis airway epithelia. Nature 1986; 322: 467-70.

6 Frizzell RA, Rechkemmer G, Shoemaker RL. Altered regulation of airway epithelial cell chloride channels in cystic fibrosis. Science 1986; 233: 558-60.

7 Dodge JA. Gastrointestinal tract and nutrition in cystic fibrosis: pathophysiology. J Soc Med 1986; 79: suppl. 12: 27-31.

8 Turnberg LA. Control of intestinal secretion. Scand J Gastroenterol 1983; [Suppl 87] 85-9.

9 Taylor CJ, Baxter PS, Hardcastle J, Hardcastle PT. Absence of secretory response in jejunal biopsy samples from children with cystic fibrosis. Lancet 1987; ii: 107-8.

10 Quinton PM. Missing $\mathrm{Cl}$ conductance in cystic fibrosis. Am J Physiol 1986; 251: C649-52.

11 Widdicombe JH. Cystic fibrosis and $\beta$-adrenergic response of airway epithelial cell cultures. Am J Physiol 1986; 251: R818-22.

12 Berschneider HM, Azizkhan RG, Knowles M, Boucher $\mathrm{R}$, Powell DW. Intestinal electrolyte transport in cystic fibrosis. Gastroenterology 1987; 92: 1315.

13 Hardcastle J, Hardcastle PT. Membrane permeability changes in intestinal secretion. Med Sci Res 1987; 15: $471-3$.

14 Sato K, Sato F. Defective beta adrenergic response of cystic fibrosis sweat glands in vivo and in vitro. J Clin Invest 1984; 73: 1763-71.

15 Bolton JE, Field M. Ca ionophore-stimulated ion secretion in rabbit ileal mucosa: relation to actions of cyclic $3^{\prime}, 5^{\prime}$-AMP and carbamylcholine. J Membrane Biol 1977; 35: 159-73.

16 Pedersen PS, Larsen EH, Brandt MJ. Restitution of chloride permeability in cystic fibrosis. Med Sci Res 1987; 15: 151-2.

17 Rohde JE, Andersen B. In vitro measurement of ion fluxes across biopsies of human jejunal mucosa during cholera. J Appl Physiol 1973; 35: 557-61. 
18 Bukhave K, Rask-Madsen J. Saturation kinetics applied to in vitro effects of low prostaglandin $E_{2}$ and $F_{2 \alpha}$ concentrations on ion transport across human jejunal mucosa. Gastroenterology 1980; 78: 32-42.

19 Isaacs PET, Corbett CL, Riley AK, Hawker PC, Turnberg LA. In vitro behaviour of human intestinal mucosa. The influence of acetyl choline on ion transport. J Clin Invest 1976; 58: 535-42.

20 Schultz SG, Zalusky R. Ion transport in isolated rabbit ileum. II. The interaction between active sodium and active sugar transport. J Gen Physiol 1964; 47: 1043-59.

21 Giraldez F, Sepúlveda FV. Changes in apparent chloride permeability of Necturus enterocytes during socium-coupled transport. Biochim Biophys Acta 1987; 898: $248-52$.

22 Boyd CAR. Absence of secretory response in jejunal biopsy samples from children with cystic fibrosis. Lancet 1987; ii: 389. 